\title{
The influence of psychosocial factors at work and life style on health and work ability among professional workers
}

\author{
T. I. J. van den Berg $\cdot$ S. M. Alavinia $\cdot$ F. J. Bredt $\cdot$ \\ D. Lindeboom $\cdot$ L. A. M. Elders $\cdot$ A. Burdorf
}

Received: 15 June 2007 / Accepted: 10 December 2007 / Published online: 3 January 2008

(C) The Author(s) 2007

\begin{abstract}
Objectives The purpose of this article is to explore the associations of psychosocial factors at work, life style, and stressful life events on health and work ability among white-collar workers.

Methods A cross-sectional survey was conducted among workers in commercial services $(n=1141)$. The main outcome variables were work ability, measured by the work ability index (WAI), and mental and physical health, measured by the Short-Form Health Survey (SF-12). Individual characteristics, psychosocial factors at work, stressful life events, and lifestyle factors were determined by a questionnaire. Maximum oxygen uptake, weight, height, and biceps strength were measured during a physical examination.

Results Work ability of white-collar workers in commercial services industry was strongly associated with psychosocial factors at work such as teamwork, stress handling, and self-development and, to a lesser extent, with stressful life events, lack of physical activity, and obesity. Determinants of mental health were very similar to those of work ability, whereas physical health was influenced primarily by life style factors. With respect to work ability, the influence of unhealthy life style seems more important for older workers, than for their younger colleagues.

Conclusion Among white-collar workers mental and physical health were of equal importance to work ability,

T. I. J. van den Berg · S. M. Alavinia - L. A. M. Elders ·

A. Burdorf $(\square)$

Department of Public Health, Erasmus MC,

University Medical Center Rotterdam,

PO Box 2040, 3000 CA Rotterdam, The Netherlands

e-mail: a.burdorf@erasmusmc.nl

F. J. Bredt $\cdot$ D. Lindeboom

Lifeguard, Utrecht, The Netherlands
\end{abstract}

but only mental health and work ability shared the same determinants. The strong associations between psychosocial factors at work and mental health and work ability suggest that in this study population health promotion should address working conditions rather than individual life style factors.

Keywords Work ability · Functional health . Psychosocial factors - Physical activity

\section{Introduction}

Many western countries face the challenge of an aging population, which also affects the workforce. From the biological perspective, aging means a progressive deterioration in various physiological systems, which is accompanied by changes in physical and mental capacities of workers (Ilmarinen, 1997). Aging of the workforce will result in an increased prevalence of work-relevant symptoms and diseases. Therefore, the role of (functional) health in working life is of interest, especially since modern welfare states are prolonging working life by increasing the statutory retirement age. A recent study on the relation between health and working life showed that a perceived poor health predicts staying or becoming unemployed (Schuring et al. 2007). This calls for better adjustments of the working life demands with the individual's health as a crucial element for a longer career at work. Within this framework, the concept of work ability has been developed as an important tool to identify workers at risk for imbalance between health, capabilities and demands at work.

The work ability concept is based on the assumption that work ability is determined by an individual's perception of the demands at work and the ability to cope with them. The 
work ability index (WAI) is a well-accepted instrument to conceptualize work ability. Several studies have shown that a low score on the index is highly predictive of work disability during follow-up (Liira et al. 2000; Tuomi et al. 1991). Previous research, predominantly in physically demanding jobs, showed that the WAI is negatively influenced by older age, high physical work demands, high psychosocial work demands (e.g. lack of possibilities to control one's own work), unhealthy lifestyle (lack of physical activity), and a poor physical fitness (Alavinia et al. 2007; Ilmarinen et al. 1997; Pohjonen, 2001a; Tuomi et al. 2001).

Few studies have addressed determinants of work ability in occupational populations with predominantly mental demands at work. Among office workers Sjögren-Rönkä (2002) showed that low stress at work and a better self-confidence were directly related to higher work ability. Seniority in the job and job satisfaction were also associated with a better work ability among office workers (Martinez and Latorre 2006). However, the knowledge of determinants of work ability in mentally demanding occupations is scarce and hence, it remains unclear whether in these jobs the relative importance of personal and work-related factors is similar to their well-known contribution in physically demanding jobs.

The purpose of this study was to explore the associations of psychosocial factors at work, stressful life events, and life style on health and work ability among white-collar workers.

\section{Methods}

\section{Subjects}

In the period between 2003 and 2007 a total of 2,666 whitecollar workers from six companies in commercial services were invited for a health examination. Twenty percent of the subjects were employed at three consultancy firms, $62 \%$ at two insurance companies and $18 \%$ at an information technology company. The health examination consisted of two parts, i.e. a questionnaire and a physical examination. Both parts were offered independently to workers and their participation was entirely voluntary. The response to the questionnaire was $69.4 \%(n=1,850)$. The response to the physical examination was $67.8 \%(n=1808)$. Selection of subjects with both a filled out questionnaire and a physical examination comprised the study population of 1141 $(42.8 \%)$ subjects.

\section{Work ability}

Work ability was measured with the work ability index (WAI). The WAI consists of an assessment of the physical and mental demands on an individual in relation to his work, previously diagnosed diseases, limitations in work due to disease, sick leave, work ability prognosis, and psychological resources. The WAI consists of seven dimensions and the index is derived as the sum of the ratings on these dimensions. The range of the summative index is $7-49$, which is classified into a poor (7-27), moderate (28-36), good (37-43), or excellent (44-49) work ability (Tuomi et al. 1998).

Functional health status

Functional health status was assessed using the Short-Form Health Survey (SF-12) version 2, the shortened alternative for the 36-item health survey. This measure provides two weighted summary scores assessing physical function (physical health component summary, PCS) and mental well-being (mental health component summary, MCS) (Ware et al., 2002). The mental health summary score ranges from 8 to 74 , whereas the physical health summary score ranges from 4 to 73 , with a higher score indicating a better health state.

\section{Psychosocial factors at work}

Psychosocial factors at work were measured by the stress monitor (Petri et al. 2001). The original monitor consists of four dimensions, whereas three dimensions (teamwork, stress handling, and self-development) were used in the current study. The three dimensions consist of 27 items on a five-point scale varying from "totally disagree" to "totally agree". The dimension teamwork (Cronbach's alpha $=0.85)$ reflects social support and work spirit and consists of 12 items, e.g. "I can rely on my colleagues and trust them" and "We are not a team at work". The stresshandling dimension (Cronbach's alpha $=0.77$ ) reflects active coping and self-efficacy and consists of seven items, such as "In difficult situations I do not wait and see, but take action" and "I can cope well with the demands of my job". The dimension self-development (Cronbach's alpha $=0.82)$ reflects possibilities for self-fulfilment and consists of eight items. Examples are: "My abilities are full employed" and "I need a new challenge". The scores on items within each dimension were transformed to a $0-100$ scale with a higher score indicating good teamwork, better stress handling, and more opportunities for self-development in work. The sum scores for the variables teamwork, stress handling, and self-development were not normally distributed. Tertiles were calculated to assign subjects into low, intermediate and high levels per dimension.

\section{Stressful life events}

The occurrence of stressful life events in the past 12 months was measured using a shortened social readjustment rating 
questionnaire (SRRQ) (Holmes and Rahe 1967). The original SRRQ consists of 43 life events (e.g., divorce, job change, death of family members and so forth), listed by rank order based on their mean life change values. Life change values classify the impact of the events and were obtained by scaling the life events based on the amount of coping required to deal with the event. The total score counts the life change values of all events in the past 12 months. In the current study the 25 events most appropriate for the population under study were selected. In theory, the total score can range from none of these events (0) up to all events (1077).

\section{Life style factors}

Life style factors were measured with the Dutch version of the Stanford wellness inventory (Sallis et al. 1985). Lifestyle factors of interest concerned moderate physical activity, vigorous activity, smoking, and alcohol use. The questionnaire has single questions on regular participation in moderate activities for 30 minutes or more and participation in vigorous activities for $20 \mathrm{~min}$ or more, both on a five-point scale ranging from "never" to "5 days or more per week". Those who reported moderate physical activity on at least 5 days per week were considered in agreement with the recommendation on moderate-intensity physical activity, and subjects with vigorous exercises at least 3 times per week were considered in agreement with the recommendation on vigorous-intensity physical activity (Pate et al. 1995). Current smoking was assessed with the question "Do you smoke?". A five-point-response scale was used to assess alcohol drinking by average number of alcohol drinks per week $(1-7,8-14,15-21,22-28$, more than 28). Problematic drinkers were defined as those who consumed more than 14 units of alcohol per week for women and more than 21 units for men (Health Council Netherlands 2006).

\section{Physical examination}

Physical examinations were performed using MicroFit equipment in accordance with the protocol of the American College of Sports Medicine (ACSM, 1975). During the physical examination biometry was recorded, including weight, height, biceps strength, and cardio respiratory fitness. The body mass index (BMI) was used to define subjects as normal (BMI $\leq 25)$, overweight (BMI 25-30), or obese $(\mathrm{BMI} \geq 30)$. Maximal isometric muscular strength of the biceps was measured after one practice trial with a calibrated dynamometer with the subjects in standing position with $90^{\circ}$ flexion in the elbows for $3 \mathrm{~s}$. The isometric biceps strength was calculated as the average of several hundred readings over the $3 \mathrm{~s}$ period. Cardio respiratory fitness was assessed by a $12 \mathrm{~min}$ submaximal bicycle ergometer test, supervised by instructors. Subjects pedaled at $60 \mathrm{rev} \cdot \mathrm{min}^{-1}$ for $12 \mathrm{~min}$ on the cycle ergometer, at an exercise intensity designed to produce a heart rate between 120 and 170 beats $\mathrm{min}^{-1}$, in order to reach a level of $80 \%$ of the theoretical maximal heart rate of the participant for $3 \mathrm{~min}$, after a warming up period of minimal $3 \mathrm{~min}$. This level was sustained for $3 \mathrm{~min}$ and the heart rate was measured at the end of each minute. The $\mathrm{VO}_{2} \max \left(\mathrm{mL} \mathrm{min}{ }^{-1} \mathrm{~kg}^{-1}\right.$ ) was calculated by the work intensity (watts) and heart rates at the end of all the stages at exercise level.

\section{Statistics}

The effects of individual characteristics (age and sex), life style, psychosocial factors at work, stressful life events, life style, and physical condition on the outcome variables work ability, and mental and physical health were investigated with linear regression analysis. Probability plots and Kolmogorov-Smirnov tests showed that none of the determinants measured at continuous level were normally distributed. However, the evaluation of the distributions of residuals in the regression analyses showed that for those variables measured at ratio scale (i.e. age, $\mathrm{VO}_{2} \max$, and biceps strength), the assumption of linearity was not violated. These variables were included in the linear regression analyses as continuous variables. Due to considerable ceiling effects for the psychosocial variables and skewed distribution for life stress events, these variables were treated as categorical variables, defined by cut-off values based on tertiles.

The analysis started with univariate regression models to determine the single effects of all determinants of interest. A backward regression technique was used to determine the multivariate model with the best overall fit. In this analysis, independent variables with a $P$-value of 0.05 or less were retained in the final model.

The results of the regression analyses are presented by the regression coefficients and associated standard errors. A regression coefficient is an expression of the change in the work ability score due to a change in one unit of measurement of the independent variable of interest. For categorical variables, this reflects the effect on the work ability score of the presence of this determinant.

The regression analysis on determinants of work ability was stratified for three age groups. All significant determinants in the multivariate model for one age group were included in the models for other age groups as well in order to provide an appropriate comparison.

All analyses were carried out with the statistical package for social sciences version 11.0 for Windows (SPSS, 1999). 


\section{Results}

The study population included 769 men (67\%) and 372 $(33 \%)$ women in a variety of jobs (Table 1). The median for age was 35.7 years (18-63). The distribution of excellent, good, moderate, and poor work ability was 42.8, 45.4, 9.7, and $2.1 \%$, respectively. Subjects scored almost equal on mental health as on physical health, whereas the Pearson correlation coefficient between both measures of health was -0.20 . The Pearson correlation coefficients between WAI and mental and physical health were 0.49 and 0.35 , respectively. The three psychosocial factors at work were strongly interrelated with Pearson correlation coefficients varying from 0.45 to 0.57 .

Table 2 shows mental health was statistically significant influenced by psychosocial factors at work, stressful life events, and, life style factors, whereas physical health was influenced by lifestyle factors and physical condition in the univariate model. The multivariate model explained $22 \%$ of the variance in mental health. An increase in age with one year increased the mental health score with 0.1 point, and decreased the physical health score with 0.1 point. In the multivariate analysis most determinants remained statistically significant, albeit with a lower regression coefficient, especially for teamwork and self-development. The multivariate model explained only $5 \%$ of the variance in physical health. It is of interest to note that neither problematic alcohol use nor overweight or obesity was associated with physical health.

Table 3 shows work ability was statistically significant influenced by psychosocial factor at work, stressful life events, lack of vigorous physical activity, and obesity in the univariate model. The multivariate model explained $29 \%$ of the variance in work ability. Again, in the multivariate model most determinants remained statistically significant, although with lower regression coefficients. The influence of stressful life events increased in the multivariate model.

No significant interaction was observed for age, sex, and psychosocial factors at work.

Table 4 shows that in each age group sex, stress handling, and self-development were associated with the work ability index. Lifestyle factors were associated with work ability only in the oldest age group of workers, over 45 years. Obesity no longer was statistically significant.
Table 1 Characteristics of 1,141 commercial workers who participated in a voluntary medical examination

\begin{tabular}{|c|c|c|c|}
\hline Characteristics & Cases & Median (min-max) & Frequency $(\%)$ \\
\hline \multicolumn{4}{|l|}{ Individual characteristics } \\
\hline Age (year) & 1,141 & $35.7(18-63)$ & 67.4 \\
\hline Male & 769 & & \\
\hline \multicolumn{4}{|l|}{ Work ability } \\
\hline Excellent (44-49) & 488 & $42.1(9-49)$ & 42.8 \\
\hline Good (37-43) & 518 & & 45.4 \\
\hline Moderate (28-36) & 111 & & 9.7 \\
\hline Poor (7-27) & 24 & & 2.1 \\
\hline \multicolumn{4}{|l|}{ Health } \\
\hline Mental health component summary (MCS) (8-74) & 1,141 & $54.2(10.9-67.9)$ & \\
\hline Physical health component summary (PCS) (4-73) & 1,141 & $53.4(18.2-70.6)$ & \\
\hline \multicolumn{4}{|l|}{ Psychosocial factors at work } \\
\hline Teamwork $(0-100)$ & 1,136 & $81.0(27-100)$ & \\
\hline Stress-handling (0-100) & 1,136 & $68.0(11-100)$ & \\
\hline Self-development $(0-100)$ & 1,136 & $78.0(9-100)$ & \\
\hline Stressful life events $(0-100)$ & 1,136 & $5.5(0-38.4)$ & \\
\hline \multicolumn{4}{|l|}{ Life style } \\
\hline Lack of moderate physical activity $\left(<5\right.$ days week $\left.{ }^{-1}\right)$ & 798 & & 70.2 \\
\hline Lack of vigorous physical activity ( $<3$ times week ${ }^{-1}$ ) & 886 & & 78.0 \\
\hline Current smoker & 145 & & 12.8 \\
\hline Problematic alcohol use & 42 & & 4.5 \\
\hline \multicolumn{4}{|l|}{ Physical examination } \\
\hline Overweight (BMI 25-30 $\mathrm{kg} \mathrm{m}^{-2}$ ) & 371 & $35.9(11.4-61.7)$ & 34.6 \\
\hline Obesity (BMI $\geq 30 \mathrm{~kg} \mathrm{~m}^{-2}$ ) & 57 & $37.0(8.0-94.0)$ & 5.3 \\
\hline $\mathrm{VO}_{2} \max \left(\mathrm{ml} \mathrm{kg}^{-1} \min ^{-1}\right)$ & 1,117 & & \\
\hline Biceps strength $(\mathrm{kg})$ & 1,134 & & \\
\hline
\end{tabular}


Table 2 Results of backward regression analysis: effects of psychosocial factors at work, stressful life events, lifestyle and physical condition on mental health and physical health among workers in commercial services $(n=1141)$

\begin{tabular}{|c|c|c|c|c|c|c|c|c|}
\hline & \multicolumn{4}{|c|}{ Mental Health (MCS) } & \multicolumn{4}{|c|}{ Physical health (PCS) } \\
\hline & \multicolumn{2}{|c|}{ Univariate model } & \multicolumn{2}{|c|}{ Multivariate model } & \multicolumn{2}{|c|}{ Univariate model } & \multicolumn{2}{|c|}{ Multivariate model } \\
\hline & $\beta$ & $S E$ & $\beta$ & $S E$ & $\beta$ & $S E$ & $\beta$ & $S E$ \\
\hline \multicolumn{9}{|l|}{ Individual characteristics } \\
\hline Age (year) & $0.09 *$ & 0.03 & $0.07 *$ & 0.02 & $-0.07 *$ & 0.02 & $-0.09 *$ & 0.02 \\
\hline Male & $2.41 *$ & 0.51 & $1.52 *$ & 0.47 & $1.66^{*}$ & 0.38 & $1.91 *$ & 0.38 \\
\hline \multicolumn{9}{|l|}{ Psychosocial factors at work } \\
\hline Low versus high teamwork & $-5.90^{*}$ & 0.56 & $-2.71 *$ & 0.66 & $-0.92 *$ & 0.43 & n.s. & \\
\hline Intermediate high versus teamwork & $-2.39^{*}$ & 0.57 & -0.70 & 0.58 & -0.68 & 0.45 & n.s. & \\
\hline Low versus high stress-handling & $-6.94 *$ & 0.56 & $-4.71 *$ & 0.62 & -0.26 & 0.45 & n.s. & \\
\hline Intermediate versus high stress-handling & $-2.39 *$ & 0.58 & $-1.42 *$ & 0.59 & 0.01 & 0.46 & n.s. & \\
\hline Low versus high self-development & $-5.44 *$ & 0.60 & $-2.12 *$ & 0.65 & -0.73 & 0.46 & n.s. & \\
\hline Intermediate versus high self-development & $-2.19^{*}$ & 0.58 & -0.59 & 0.57 & -0.81 & 0.45 & n.s. & \\
\hline \multicolumn{9}{|l|}{ Stressful life events } \\
\hline High versus low stressful life events & $-3.13^{*}$ & 0.59 & $-3.13^{*}$ & 0.54 & -0.62 & 0.44 & n.s. & \\
\hline Intermediate versus low stressful life events & $-1.91 *$ & 0.59 & $-1.98^{*}$ & 0.53 & -0.05 & 0.44 & n.s. & \\
\hline \multicolumn{9}{|l|}{ Life style } \\
\hline Lack of moderate physical activity & -0.14 & 0.53 & n.s. & & -0.01 & 0.39 & n.s. & \\
\hline Lack of vigorous physical activity & $-1.27 *$ & 0.58 & $-1.37 *$ & 0.52 & $-1.79 *$ & 0.43 & $-1.71 *$ & 0.42 \\
\hline Current smoker & $-2.02 *$ & 0.72 & $-1.96^{*}$ & 0.65 & $-1.14 *$ & 0.54 & n.s. & \\
\hline Problematic alcohol use & -1.76 & 1.27 & n.s. & & -1.61 & 0.92 & n.s. & \\
\hline \multicolumn{9}{|l|}{ Physical examination } \\
\hline Obesity (BMI $\geq 30)$ versus normal $(\mathrm{BMI}<25)$ & -0.84 & 1.14 & n.s & & -1.54 & 0.83 & n.s. & \\
\hline Overweight (BMI 25-30) versus normal & 0.34 & 0.54 & n.s & & -0.30 & 0.39 & n.s. & \\
\hline $\mathrm{VO}_{2} \max (\mathrm{ml} / \mathrm{kg} / \mathrm{min})$ & -0.01 & 0.03 & n.s & & $0.05 *$ & 0.02 & n.s. & \\
\hline Biceps strength (kg) & 0.03 & 0.02 & n.s & & $0.04 *$ & 0.02 & n.s. & \\
\hline
\end{tabular}

n.s not significant, $P>0.05$

\section{Discussion}

This study showed that work ability of white-collar workers in commercial services industry was strongly associated with psychosocial factors at work, such as teamwork, stress handling, self-development, and, to a lesser extent, with stressful life events, lack of physical activity, and obesity. Work ability was strongly associated with mental and physical health. Determinants of mental health were very similar to those of work ability, whereas physical health was influenced primarily by lack of life physical activity.

Some limitations must be taken into account in this study. First, the cross-sectional design does not permit exploration of causal relationships between the determinants and work ability. Therefore, it remains unknown whether, for example, poor stress handling will decrease work ability or decreased work ability will cause a poorer stress handling. Nevertheless, the results are still of interest as they give a first insight into important factors for interventions among white-collar workers. Second, data were drawn from voluntary participants. Information on nonresponse for both measures showed that age and sex did not bias response. Non-response differences between questionnaire and physical examination did not show any bias; none of the questionnaire variables were associated with not participating in the physical examination; and also none of the physical examination variables were associated with not participating in the questionnaire. Third, the reliability of the physical examination highly depends on the professional skills of the instructor and the standardization of the examination. The maximum oxygen uptake was indirectly calculated using the heart rate, which can be easily increased by minor distractions, such as room temperature, and talking during the test.

In this study among white-collar workers in commercial services industry, the proportion of workers with poor work ability was $2.1 \%$ and the mean WAI was $41.1(\mathrm{SD}=5.1$ ). These results are slightly higher than the Finnish reference data in mentally demanding work (mean 39) (Tuomi et al. 1998). 
Table 3 Results of backward regression analysis: effects of psychosocial factors at work, stressful life events, lifestyle and physical condition on work ability among workers in commercial services $(n=1141)$

n.s not significant, $P>0.05$

\begin{tabular}{|c|c|c|c|c|}
\hline & \multirow{2}{*}{\multicolumn{2}{|c|}{$\frac{\text { Work ability }}{\text { Univariate model }}$}} & \multirow{2}{*}{\multicolumn{2}{|c|}{$\frac{\text { Work ability }}{\text { Multivariate model }}$}} \\
\hline & & & & \\
\hline & $\beta$ & $S E$ & $\beta$ & $S E$ \\
\hline \multicolumn{5}{|l|}{ Individual characteristics } \\
\hline Age (year) & $-0.07 *$ & 0.02 & $-0.09 *$ & 0.01 \\
\hline Male & $2.13^{*}$ & 0.31 & $2.08 *$ & 0.28 \\
\hline \multicolumn{5}{|l|}{ Psychosocial factors at work } \\
\hline Low versus high teamwork & $-4.02 *$ & 0.32 & $-1.32 *$ & 0.40 \\
\hline Intermediate versus high teamwork & $-1.52 *$ & 0.34 & -0.20 & 0.35 \\
\hline Lowversus versus high stress-handling & $-4.39 *$ & 0.34 & $-2.75^{*}$ & 0.35 \\
\hline Intermediate versus high stress-handling & $-1.41 *$ & 0.35 & $-0.79 *$ & 0.35 \\
\hline Low versus high self-development & $-4.11^{*}$ & 0.35 & $-2.20 *$ & 0.39 \\
\hline Intermediate versus high self-development & $-1.67 *$ & 0.34 & $-0.91^{*}$ & 0.34 \\
\hline \multicolumn{5}{|l|}{ Stressful life events } \\
\hline High versus low stressful life events & $-1.36^{*}$ & 0.36 & $-2.01 *$ & 0.32 \\
\hline Intermediate versus low stressful life events & $-0.97 *$ & 0.36 & $-1.14^{*}$ & 0.32 \\
\hline \multicolumn{5}{|l|}{ Life style } \\
\hline Lack of moderate physical activity & 0.49 & 0.32 & n.s & 0.31 \\
\hline Lack of vigorous physical activity & $-0.71 *$ & 0.35 & $-0.71^{*}$ & \\
\hline Current smoker & -0.68 & 0.44 & n.s. & \\
\hline Problematic alcohol use & -0.52 & 0.74 & n.s. & \\
\hline \multicolumn{5}{|l|}{ Physical examination } \\
\hline Obesity (BMI $\geq 30$ ) versus normal $(\mathrm{BMI}<25)$ & $-2.02 *$ & 0.68 & $-1.21^{*}$ & 0.59 \\
\hline Overweight (BMI 25-30) versus normal $(\mathrm{BMI}<25)$ & -0.49 & 0.32 & -0.32 & 0.28 \\
\hline $\mathrm{VO}_{2} \max \left(\mathrm{ml}^{-1} \mathrm{~kg}^{-1} \mathrm{~min}\right)$ & 0.03 & 0.02 & n.s. & \\
\hline Biceps strength $(\mathrm{kg})$ & 0.03 & 0.01 & n.s. & \\
\hline
\end{tabular}

Work ability in this study population was influenced by sex, age, psychosocial factors at work, stressful life events, and life style factors. These factors together explained $29 \%$ of the total variance in work ability in this study population. Male sex increased work ability with two points, which means $4 \%$ of the maximum score. An increase in age of 40 years decreases the WAI score with four points, which is $7.3 \%$ of the maximum score, which indicates a rather modest influence of age on work ability. Psychosocial factors each had an effect on WAI comparable to sex, whereas the combined effect of the psychosocial factors is approximately 1.5 -fold the effect of 40 years of aging. Lack of vigorous physical activity decreases the WAI score with only 0.7 points, which is no more than $1.5 \%$ of the maximum score. Obesity (5\% of the population) compared to normal weight decreases the WAI score with 1.2 points, which is $2.4 \%$ of the maximum score.

Each psychosocial factor at work was negatively associated with work ability. Univariate results showed comparable strength in associations, while the multivariate model showed lower regression coefficients, especially for teamwork. It seems that the association between teamwork and work ability was more influenced by other determinants included in the multivariate model, than the associations between work ability and stress handling and self-development.

In previous research, inconsistent results were found regarding the influence of psychosocial factors at work on work ability. For example, in the metal industry an increase in teamwork and increase in opportunities for development was not predictive of an increase in work ability during a 2-year follow-up (Tuomi et al. 2004). Negative associations between mental stress and work ability have been found among office workers $(\beta=-0.17)$, but this association was minimized when including age in the regression model (Sjögren-Rönkä, 2002). Among bus drivers, significant associations were observed for high control by superiors and lack of responsibility at work with lower WAI scores (Kloimüller et al. 2000).

The negative association of stressful life events with work ability in the current study is in agreement with earlier findings by Pohjonen (2001b), who found an increased risk for poor work ability $[O R=3.62(2.2-5.9)]$ for a hard life situation outside of work. 
Table 4 Results on backward regression analysis per age-group: effects of psychosocial factors at work, stressful life events, lifestyle and physical condition on work ability among workers in commercial services $(n=1141)$

\begin{tabular}{|c|c|c|c|c|c|c|}
\hline & \multicolumn{6}{|c|}{$\begin{array}{l}\text { Work ability } \\
\text { Multivariate model }\end{array}$} \\
\hline & \multicolumn{2}{|c|}{$\begin{array}{l}\text { Age } \leq 32 \text { year } \\
(n=335)\end{array}$} & \multicolumn{2}{|c|}{$\begin{array}{l}\text { Age } 32-45 \text { year } \\
(n=366)\end{array}$} & \multicolumn{2}{|c|}{$\begin{array}{l}\text { Age }>45 \text { year } \\
(n=200)\end{array}$} \\
\hline & $\beta$ & $S E$ & $\beta$ & $S E$ & $\beta$ & $S E$ \\
\hline \multicolumn{7}{|l|}{ Individual characteristics } \\
\hline Male & $1.43 *$ & 0.42 & $1.37 *$ & 0.49 & $3.19 *$ & 0.83 \\
\hline \multicolumn{7}{|l|}{ Psychosocial factors at work } \\
\hline Low versus high teamwork & -0.44 & 0.61 & $-1.40 *$ & 0.63 & -1.07 & 0.98 \\
\hline ntermediate versus high teamwork & -0.49 & 0.50 & -0.39 & 0.60 & -0.58 & 0.89 \\
\hline Low versus high stress-handling & $-2.85^{*}$ & 0.55 & $-3.22^{*}$ & 0.63 & $-2.44 *$ & 0.95 \\
\hline Intermediate versus high stress-handling & -0.96 & 0.52 & -1.08 & 0.61 & -0.83 & 0.86 \\
\hline Low versus high self-development & $-2.59^{*}$ & 0.64 & $-1.64 *$ & 0.59 & $-3.57 *$ & 1.01 \\
\hline Intermediate versus high self-development & $-1.27^{*}$ & 0.51 & -0.92 & 0.57 & -1.63 & 0.84 \\
\hline \multicolumn{7}{|l|}{ Stressful life events } \\
\hline High versus low stressful life events & $-1.25^{*}$ & 0.49 & $-1.67 *$ & 0.51 & $-2.60 *$ & 0.84 \\
\hline Intermediate versus low stressful life events & -0.64 & 0.53 & $-1.78^{*}$ & 0.52 & -0.34 & 0.72 \\
\hline \multicolumn{7}{|l|}{ Life style } \\
\hline Lack of moderate physical activity & -0.28 & 0.47 & 0.02 & 0.51 & $1.45^{*}$ & 0.70 \\
\hline Lack of vigorous physical activity & -0.58 & 0.49 & -0.56 & 0.53 & $-1.62 *$ & 0.79 \\
\hline Problematic alcohol use & 1.70 & 0.93 & -0.85 & 1.19 & $-2.62 *$ & 1.33 \\
\hline
\end{tabular}

$P>0.05$

The results showed that a lack of vigorous physical activity was associated with decreased work ability, whereas associations between work ability and biceps strength and maximum oxygen uptake were not found in the multivariate model. The lack of significant results for maximum oxygen uptake and biceps strength is in line with findings of Eskelinen et al. (1991), Nygard et al. (1991), and Pohjonen (2001a). It may be hypothesized that in mentally demanding jobs a good physical condition is not required to meet the work demands and, thus, will have no influence on work ability.

Stratification by age showed the importance of lifestyle in the oldest age group, but not among younger workers. This effect may be explained by the fact that health problems due to an unhealthy lifestyle, most notably diabetes mellitus and cardiovascular disease, occur primarily at older age. In the total study population, obesity was significantly associated with lower work ability, whereas no significant associations were found in the stratified analyses. This is partly due to lack of statistical power in these strata with smaller numbers of workers, since the magnitude of the regression coefficients were comparable but the standard errors increased substantially.

The Pearson correlation coefficient of mental and physical health was -0.20 , which was in line with results of van Duijn et al. (2004). In a univariate analysis both mental health and physical health were associated with work ability. However, determinants of work ability were similar to determinants of mental health. This finding can be explained by the fact that the work setting of the whitecollar workers in the current study is characterized by high mental demands. An exception to the similarity in factors influencing both mental health and work ability was, smoking. Smoking was related to mental health, but not to work ability.

The results of the current study outline the importance of work-related factors in white-collar workers, with regard to work ability. The combined impact of psychosocial factors is much stronger than is for individual factors, and is amenable to change, in contrast to individual factors as age, and sex.

In conclusion, among white-collar workers in commercial services industry psychosocial factors at work, stressful life events, lack of vigorous physical activity, and obesity were significant with regard to work ability. The strong associations between psychosocial factors at work and mental health and work ability suggest that in this study population health promotion should address working conditions rather than individual life style factors, although the importance of life style factors seems to increase with aging of the worker. 
Open Access This article is distributed under the terms of the Creative Commons Attribution Noncommercial License which permits any noncommercial use, distribution, and reproduction in any medium, provided the original author(s) and source are credited.

\section{References}

Alavinia SM, Duivenbooden van C, Burdorf A (2007) Influence of work-related factors and individual characteristics on work ability among Dutch construction workers. Scand J Work Environ Health 33:351-357

American College of Sports and Medicine (1975) ACSM's guidelines for exercise testing and prescription. 2000, 6th (edn.) In: B.A. Franklin (ed.), MH. Whaley et al. (ass.ed.), Lippincott Williams \& Wilkins, Philadelphia, PA

Duijn van M, Lötters F, Burdorf A (2004) Interrelationships between pain, disability, general health and quality of life and associations with work related and individual factors. Spine 19:2178-2183

Eskelinen L, Kohvakka A, Merisalo T, Hurri H, Wägar G (1991) Relationship between the self-assessment and clinical assessment of health status and work ability. Scand J Work Environ Health 17(S 1):40-47

Health Council of the Netherlands (2006) Guidelines for a healthy diet. Health Council of the Netherlands. Publication no. 2006/21, The Hague

Holmes TH, Rahe RH (1967) The social readjustment rating scale. J Psychosom Res 11:213-218

Ilmarinen J (1997) Aging and work-coping with strengths and weaknesses. Scand J Work Environ Health 23:3-5

Kloimüller I, Karazman H, Geissler I, Karazman-Morawetz I (2000) The relation of age, work ability index and stress-inducing factors among bus drivers. Int J Ind Ergonom 25:497-502

Liira J, Matikainen E, Leino-Arjas P, Malmivaara A, Mutanen P, Rytkönen H, Juntunen J (2000) Work ability of middle-aged Finnish construction workers-a follow-up study in 1991-1995. Int J Ind Ergonom 25:477-481

Martinez MC, Latorre MRDO (2006) Health and work ability among office workers. Rev Saúde Pública 40:851-858

Nygård C, Eskelinen L, Suvanto S, Tuomi K, Ilmarinen J (1991) Associations between functional capacity and work ability among elderly municipal employees. Scand J Work Environ Health 17(S 1):122-127
Pate RR, Pratt M, Blair SN, Haskell WL, Macera CA, Bouchard C et al (1995) Physical activity and public health: a recommendation from the Centers for Disease Control and Prevention and the American College of Sports Medicine. J Am Med Assoc 273:402-407

Petri C, van der Velden PG, Kleber RJ (2001) Hoe gaat het met u?een praktische Stress monitor [How are you?-A practical stress monitor]. Thema, Zaltbommel

Pohjonen T (2001a) Age-related physical fitness and the predictive values of fitness tests for work ability in home care work. J Occup Environ Med 43:723-730

Pohjonen T (2001b) Perceived work ability of home care workers in relation to individual and work-related factors in different age groups. Occup Med 51:209-217

Sallis JF, Haskell WL, Wood PD, Fortmann SP, Rogers T, Blair SN et al (1985) Physical activity assessment methodology in the Stanford five-city project. Am J Epidemiol 121:91-106

Schuring M, Burdorf A, Kunst AE, Mackenbach JP (2007) Socio-economic inequalities in health and its effect on entering and maintaining paid employment: evidence in European countries. J Epidemiol Community Health 61:597-604

Sjögren-Rönkä T, Ojanen MT, Leskinen EK, Mustalampi ST, Mälkiä EA (2002) Physical and psychosocial prerequisites of functioning in relation to work ability and general subjective well-being among office workers. Scand J Work Environ Health 28:184-190

Statistical package for social sciences (SPSS), version 11 (1999) Chigago, IL

Tuomi K, Toikkanen J, Eskelinen L, Backman AL, Ilmarinen J, Jarvinen E, Klockars M (1991) Mortality, disability and changes in occupation among aging municipal employees. Scand J Work Environ Health 17(S 1):58-66

Tuomi K, Ilmarinen J, Jahkola A, Katajarinne L, Tulkki A (1998) Work ability Index. 2nd revised edn, Occupational Health Care 19. Finnish Institute of Occupational Health, Helsinki

Tuomi K, Huuhtanen P, Nykyri E, Ilmarinen J (2001) Promotion of work ability, the quality of work and retirement. Occup Med 51:318-324

Tuomi K, Vanhala S, Nykyri E, Janhonen M (2004) Organizational practices, work demands and the well-being of employees: a follow-up study in the metal industry and retail trade. Occup Med 54:115-121

Ware JE, Kosinski MA, Turner-Bowker DM, Gandek B (2002) Sf$12 \mathrm{v} 2$ How to score version 2 of the sf-12 health survey. Quality Metric Incorporated. Health Assessment Lab Boston, Massachusetts. Lincoln, Rhode Island 